\title{
A Facile and Waste-Free Strategy to Fabricate Pt-C/TiO 2 Microspheres: Enhanced Photocatalytic Performance for Hydrogen Evolution
}

\author{
Hui Li, ${ }^{1}$ Xiaoyan Zhang, ${ }^{2}$ and Xiaoli Cui ${ }^{1}$ \\ ${ }^{1}$ Department of Materials Science, Fudan University, Shanghai 200433, China \\ ${ }^{2}$ Key Laboratory of Materials for High-Power Laser, Shanghai Institute of Optics and Fine Mechanics, \\ Chinese Academy of Sciences, Shanghai 201800, China
}

Correspondence should be addressed to Xiaoli Cui; xiaolicui@fudan.edu.cn

Received 14 June 2014; Revised 11 July 2014; Accepted 12 July 2014; Published 5 August 2014

Academic Editor: Tian-Yi Ma

Copyright (C) 2014 Hui Li et al. This is an open access article distributed under the Creative Commons Attribution License, which permits unrestricted use, distribution, and reproduction in any medium, provided the original work is properly cited.

\begin{abstract}
A facile and waste-free flame thermal synthesis method was developed for preparing Pt modified $\mathrm{C} / \mathrm{TiO}_{2}$ microspheres $\left(\mathrm{Pt}-\mathrm{C} / \mathrm{TiO}{ }_{2}\right)$. The photocatalysts were characterized with X-ray diffraction, field emission scanning electron microscopy, transmission electron microscope, ultraviolet-visible (UV-vis) diffuse reflectance spectra, X-ray photoelectron spectroscopy, and thermogravimetry analysis. The photocatalytic activity was evaluated by hydrogen evolution from water splitting under UV-vis light illumination. Benefitting from the electron-hole separation behavior and reduced overpotential of $\mathrm{H}+/ \mathrm{H}_{2}$, remarkably enhanced hydrogen production was demonstrated and the photocatalytic hydrogen generation from $0.4 \mathrm{wt} \% \mathrm{Pt}-\mathrm{C} / \mathrm{TiO} \mathrm{O}_{2}$ increased by 22 times. This study also demonstrates that the novel and facile method is highly attractive, due to its easy operation, requiring no post treatment and energy-saving features.
\end{abstract}

\section{Introduction}

Photocatalytic water splitting for hydrogen evolution has attained great significance since hydrogen has been considered to be one of the ideal green fuels and can be used directly in fuel cells as well as in fuel cell-powered vehicles. In recent years, water splitting to produce hydrogen based on semiconductors has attracted tremendous attention [16]. As a typical semiconductor material, $\mathrm{TiO}_{2}$ has been widely studied in photocatalytic area due to its abundance, photostability, chemical inertness, and low toxicity [7-10]. However, the high recombination rate of photogenerated electrons and holes in $\mathrm{TiO}_{2}$ would limit its photocatalytic activity $[11,12]$. The relatively low light harvesting efficiency behaves as another drawback of $\mathrm{TiO}_{2}$ in its photocatalytic utilization $[13,14]$. These factors strongly inhibit the extensive use of naked $\mathrm{TiO}_{2}$ in solar-driven water splitting.

In the past decades, many attempts have been made to explore new avenues to prolong the life time of photogenerated carriers for higher quantum efficiency or to narrow the band gap of $\mathrm{TiO}_{2}$ for a much larger visible fraction in its light absorption spectrum, such as modification of $\mathrm{TiO}_{2}$ through implantation of metal ions $[15,16]$, doping of nonmetal atoms $[17,18]$, and combination with other components, including secondary semiconductors $[19,20]$, noble metals $[21,22]$, and dyes $[23,24]$.

It was once proposed that carbon species incorporated in $\mathrm{TiO}_{2}$ can act as sensitizers $[25,26]$, thus enhancing the photocatalytic activity of $\mathrm{TiO}_{2}$ by expanding light absorption range into visible region. There comes introduction of several nanostructured carbon materials such as carbon nanotubes [27] and graphene [28] for enhancement of photocatalytic $\mathrm{H}_{2}$ production. Besides, Pt nanoparticles are excellent candidates to serve as cocatalysts since their Fermi-energy levels are normally more positive than the conduction band of $\mathrm{TiO}_{2}$. Thus it can attract the photon-excited electrons to suppress the possible electron-hole recombination [29, 30].

Great efforts have been made to synthesize Pt modified $\mathrm{TiO}_{2}$ composites with high electrochemical or photocatalytic activity [31-36]. Ran et al. [2] recently addressed the fact that 


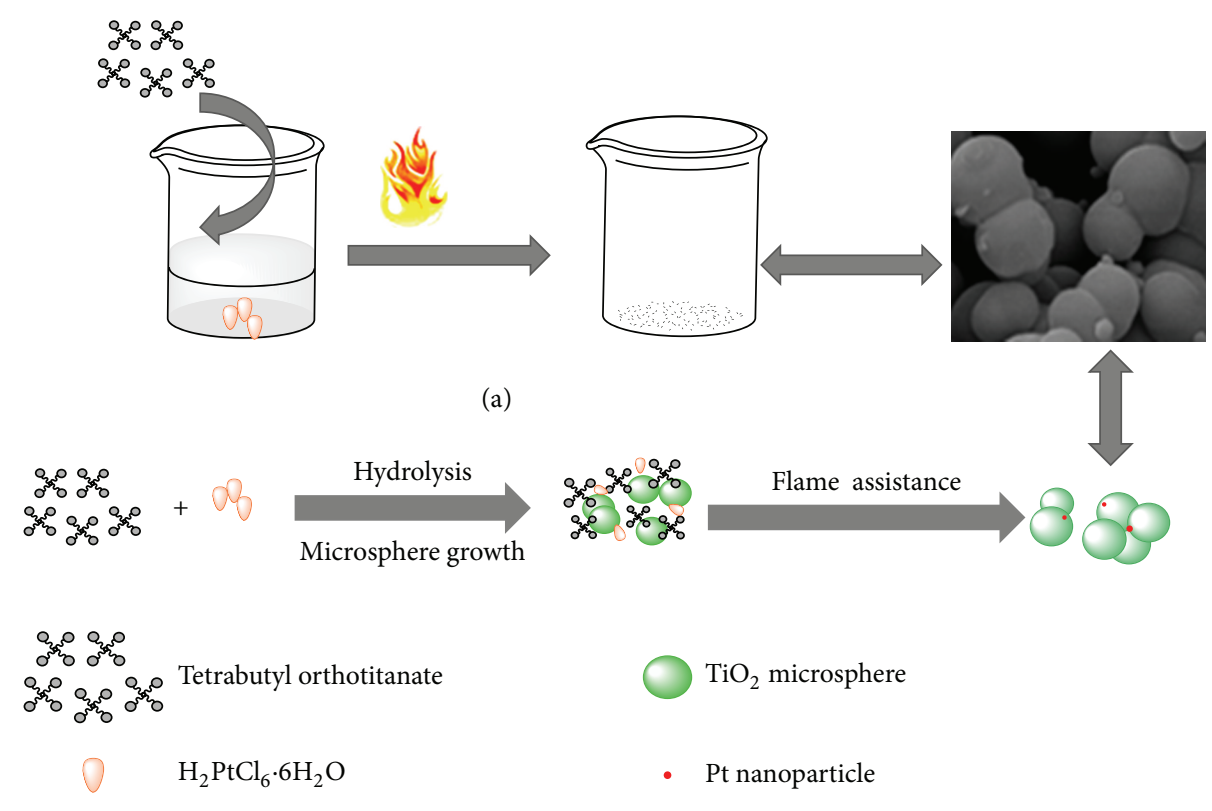

(b)

Scheme 1: (a) Schematic illustration of the fabrication procedure of $\mathrm{Pt}-\mathrm{C} / \mathrm{TiO}_{2}$ composite. (b) Schematic representation of $\mathrm{Pt}-\mathrm{C} / \mathrm{TiO}{ }_{2}$ microsphere growth process.

cocatalysts especially Pt metals are a key factor in achieving higher photocatalytic activity in most semiconductor-based photocatalytic systems. Sreethawong et al. [34] prepared Ndoped nanocrystalline mesoporous-assembled $\mathrm{TiO}_{2}$; various $\mathrm{Pt}$ contents were loaded onto the nanocomposites through the incipient wetness impregnation method. It was observed that the impregnation of $\mathrm{Pt}$ considerably improved its photocatalytic $\mathrm{H}_{2}$ production activity and the optimum Pt loading content was $1.3 \mathrm{wt} \%$. Ismail and coworkers [35] synthesized $\mathrm{Pt} / \mathrm{RuO}_{2}-\mathrm{TiO}_{2}$ photocatalysts by using photoreduction method and followed by calcination at $450^{\circ} \mathrm{C}$ for $4 \mathrm{~h}$. The asprepared samples exhibited excellent photocatalytic activity for photooxidation of $\mathrm{CH}_{3} \mathrm{OH}$ under UV light irradiation. Wang's group [36] obtained $\mathrm{Pt}$ decorated $\mathrm{TiO}_{2-x} \mathrm{~N}_{x}$ via a one-pot route. Enhanced photocatalytic activity for degradation of propylene under visible light was achieved. The improved performance was ascribed to the synergistic effect of oxygen vacancies and dopants of $\mathrm{N}$ and Pt. Although these methods have their own advantages, they are more or less limited by high temperatures or special facilities. Therefore, developing a more facile approach to fabricate Pt based $\mathrm{TiO}_{2}$ photocatalysts is still very necessary.

Recently, we have reported an easy route for constructing $\mathrm{C} / \mathrm{TiO}_{2}$ [37], $\mathrm{Fe}-\mathrm{C} / \mathrm{TiO}_{2}$ [16], $\mathrm{SiO}_{x}-\mathrm{C} / \mathrm{TiO}_{2}$ [38], and $\mathrm{Ta}_{2} \mathrm{O}_{5}$ [3] photocatalysts. Our strategy featured with short reaction time, easy operation, low cost, waste free and only one step to obtain the final $\mathrm{TiO}_{2}$. In the present work, we further introduced $\mathrm{Pt}$ to modify $\mathrm{C} / \mathrm{TiO}_{2}$ in order to achieve higher activity for the photocatalysts. The synthesis of $\mathrm{Pt}-\mathrm{C} / \mathrm{TiO}_{2}$ nanomaterials via the simple flame thermal approach was achieved and their higher performance was revealed as desired. The influence of Pt content on the phase, microstructures, and optical and photocatalytic properties was investigated in detail.

\section{Experimental}

2.1. Materials. Tetrabutyl orthotitanate (TBOT, CP) was purchased from Sinopharm Group Chemical Reagent Company, and the stated purity was $98 \%$; absolute ethanol (>97\%) and chloroplatinic acid $\left(\mathrm{H}_{2} \mathrm{PtCl}_{6} \cdot 6 \mathrm{H}_{2} \mathrm{O}, \mathrm{AR}\right)$ were obtained from Shanghai Zhenxing No. 1 Chemical Plant. All of the chemicals were used as received.

2.2. Preparation of $\mathrm{Pt}-\mathrm{C} / \mathrm{TiO}_{2}$. A series of $\mathrm{Pt}-\mathrm{C} / \mathrm{TiO}_{2}$ nanocomposites were fabricated by using the aforementioned chemicals as starting materials, as illustrated in Scheme 1. Briefly, the specified weight of $\mathrm{H}_{2} \mathrm{PtCl}_{6} \cdot 6 \mathrm{H}_{2} \mathrm{O}$ was added into a standard beaker $(150 \mathrm{~mL})$ containing $35 \mathrm{~mL}$ of ethanol and $5 \mathrm{~mL}$ of TBOT by stirring. The obtained stable solutions were ignited by a match stick under ordinary conditions. Gray powders were obtained after gentle burning for about $30 \mathrm{~min}$. The final samples with different amount of $\mathrm{Pt}: \mathrm{C} / \mathrm{TiO}_{2}$ mass ratios were labeled as $0.1 \mathrm{wt} \%, 0.4 \mathrm{wt} \%$, and $0.6 \mathrm{wt} \% \mathrm{Pt}-$ $\mathrm{C} / \mathrm{TiO}_{2}$, respectively. For comparison, $\mathrm{C} / \mathrm{TiO}_{2}$ powders were also prepared by a similar procedure except for the absence of Pt precursor [37].

2.3. Characterizations. The structure and phase composition of the samples were examined by X-ray diffraction (XRD) on a Bruker $\mathrm{D} / 8$ advanced diffractometer using $\mathrm{Cu} \mathrm{K} \alpha$ radiation. The morphologies were characterized by field emission scanning electron microscope (FE-SEM: Philips XL30) and transmission electron microscope (TEM: JEOL 
TABLE 1: Crystal sizes, absorption edges, and band gap energies of the synthesized samples.

\begin{tabular}{lccccc}
\hline Sample & $\mathrm{P} 25$ & $\mathrm{C} / \mathrm{TiO}_{2}$ & $0.1 \mathrm{wt} \% \mathrm{Pt}-\mathrm{C} / \mathrm{TiO} \mathrm{O}_{2}$ & $0.4 \mathrm{wt} \% \mathrm{Pt}-\mathrm{C} / \mathrm{TiO}{ }_{2}$ & $0.6 \mathrm{wt} \% \mathrm{Pt}-\mathrm{C} / \mathrm{TiO}{ }_{2}$ \\
\hline $\mathrm{D}_{\mathrm{TiO}_{2}}(\mathrm{~nm})^{\mathrm{a}}$ & 20.9 & 19.6 & 20.2 & 20.6 & 20.1 \\
Absorption edge $(\mathrm{nm})$ & 394 & 423 & 438 & 456 & 471 \\
Band gap (eV) & 3.15 & 2.93 & 2.83 & 2.72 & 2.63 \\
\hline
\end{tabular}

${ }^{\mathrm{a}} \mathrm{D}_{\mathrm{TiO}_{2}}$ is calculated from the most intense diffraction peak (101) of XRD spectra of the samples.

JEM-2011, Japan). A Cary-50 Scan UV-Vis spectrophotometer was used to measure the UV-vis diffuse reflectance spectra (DRS) with the scan range in the region of $200-800 \mathrm{~nm}$. The instrument employed for X-ray photoelectron spectroscopy (XPS) studies was a RBD upgraded PHI-5000 C ESCA system (Perkin Elmer) with $\mathrm{Al} / \mathrm{Mg} \mathrm{K} \alpha$ radiation. The binding energy was corrected using the $\mathrm{Cls}$ level at $284.6 \mathrm{eV}$ as an internal standard. Thermogravimetry analysis (TGA) was carried out on a SDT-Q600 (TA Company, USA) instrument with a heating rate of $10^{\circ} \mathrm{C} \mathrm{min}^{-1}$ using oxygen as the purge gas.

2.4. Photocatalytic Activity Measurements. The photocatalytic activity of samples was measured under UV-vis light illumination by using $500 \mathrm{~W}$ Xe lamp (CHF-XM35, Trusttech Co., Ltd., Beijing) as light source. The light intensity was kept at $180 \mathrm{~mW} \mathrm{~cm}{ }^{-2}$, which was measured by an optical power meter (1 L $1400 \mathrm{~A}$, International Light). The experiments were carried out in a closed quartz reactor system. Typically, the photocatalysts $(65 \mathrm{mg})$ were suspended in an aqueous methanol solution $(80 \mathrm{~mL}$ of distilled water, $20 \mathrm{~mL}$ of methanol) by means of a magnetic stirrer within the reactor. Prior to the experiment, the mixture was dispersed by ultrasound treatment for $15 \mathrm{~min}$, followed by purging $\mathrm{N}_{2}$ gas for $30 \mathrm{~min}$. The amount of evolved $\mathrm{H}_{2}$ was determined by a GC7900 gas chromatograph (thermal conductivity detector, molecular sieve $5 \mathrm{~A}, 99.999 \% \mathrm{~N}_{2}$ carrier).

\section{Results and Discussion}

3.1. XRD Patterns. Figure 1 shows the XRD patterns of the synthesized $\mathrm{Pt}-\mathrm{C} / \mathrm{TiO}_{2}$ powders, and the patterns can be well indexed to the anatase $\mathrm{TiO}_{2}$, which were determined directly without any subsequent high temperature calcination. The peaks corresponding to Pt could not be detected in Figures $1(\mathrm{c})-1(\mathrm{e})$; this is mainly ascribed to the relatively low content of this element in the nanocomposites. Similar results can also be found in the previous report [31]. The average crystallite sizes $(D)$ calculated from the main diffraction peaks using Scherrer equation are present in Table 1. It can be seen that there is nearly no difference in the $D$ value among all the samples (ca. $20 \mathrm{~nm}$ ), implying that the introduction of Pt did not alter the crystallite size of $\mathrm{TiO}_{2}$.

3.2. SEM and TEM Images. The morphologies of the samples with various $P t$ content were characterized by SEM. As shown in Figure 2, the microsphere with a diameter of $\sim 0.5$ to $2.0 \mu \mathrm{m}$ was observed for all of the prepared samples. It has been recognized that the microspheres can allow multiple reflections and scattering of incident light, which enhances

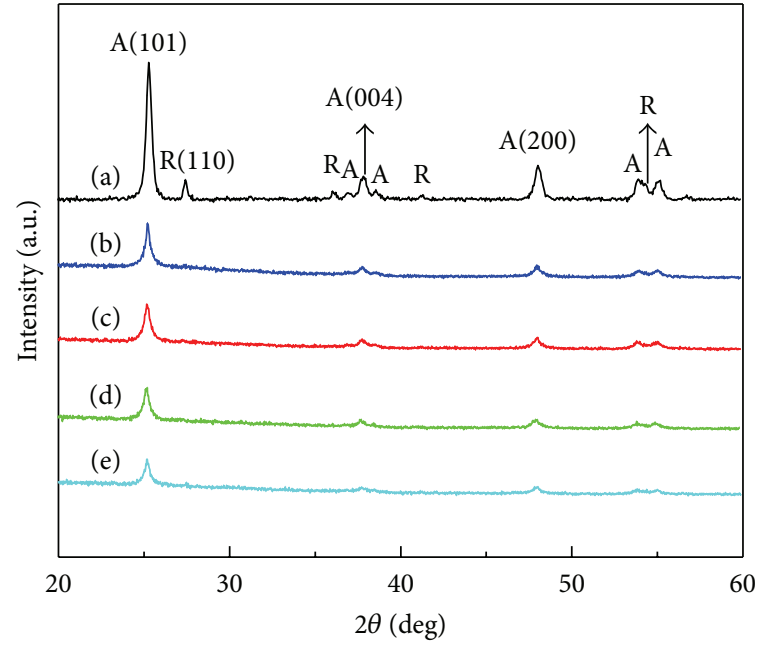

FIgure 1: XRD patterns of P25 (a), $\mathrm{C} / \mathrm{TiO}_{2}$ (b), and $\mathrm{Pt}-\mathrm{C} / \mathrm{TiO}_{2}$ composites (c)-(e). The content of Pt is $0.1 \mathrm{wt} \%$ (c), $0.4 \mathrm{wt} \%$ (d), and $0.6 \mathrm{wt} \%$ (e), respectively. (A: anatase, R: rutile.)

light harvesting and increases the quantity of photogenerated electrons and holes [37]. Therefore, it is anticipated that the photocatalytic performance will be improved for the samples. As compared with $\mathrm{C} / \mathrm{TiO}_{2}$, the introduction of $\mathrm{Pt}$ does not cause noticeable change in morphology, but more microspheres are fused together with increasing Pt content, and this change is observed more clearly in Figure 2(d). These demonstrations reveal that limited fraction of $\mathrm{Pt}$ is required to obtain relatively dispersed microspheres.

Figure 3 depicts the TEM images of $0.4 \mathrm{wt} \% \mathrm{Pt}-\mathrm{C} / \mathrm{TiO}_{2}$ nanocomposite. As displayed in Figure $3(\mathrm{a}), \mathrm{TiO}_{2}$ microsphere is composed of small primary nanoparticles of about $20 \mathrm{~nm}$ in diameter; this observation is in agreement with the XRD evaluation. The HRTEM image is presented in Figure 3(b); one can clearly observe that the lattice fringes are characteristics of the anatase $\mathrm{TiO}_{2}$ crystal, in which the d-spacing of $0.35 \mathrm{~nm}$ corresponds to the distance between the (101) planes [39]. The corresponding selectedarea electron diffraction (SAED) pattern of the nanocomposite (Figure 3(b), inset) further provides evidence of anatase structure of $\mathrm{TiO}_{2}$ with polycrystalline feature. This finding is consistent with the XRD results. Subsequent chemical composition analysis of this material by EDX spectroscopy shows the presence of $\mathrm{Pt}, \mathrm{C}, \mathrm{Ti}$, and $\mathrm{O}$ elements in the nanocomposite (Figure 3(c)), confirming that the obtained nanocomposite consists of Pt. In order to investigate the shape and size of Pt particles, we synthesized an additional 


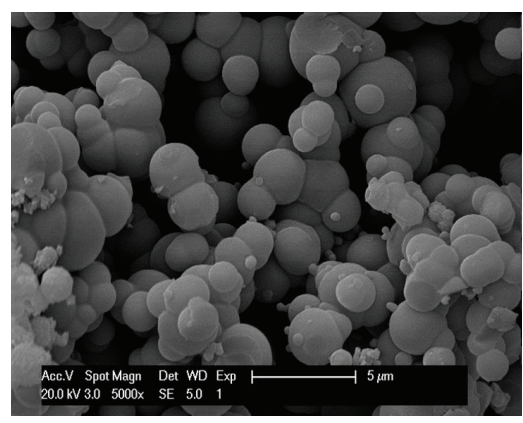

(a)

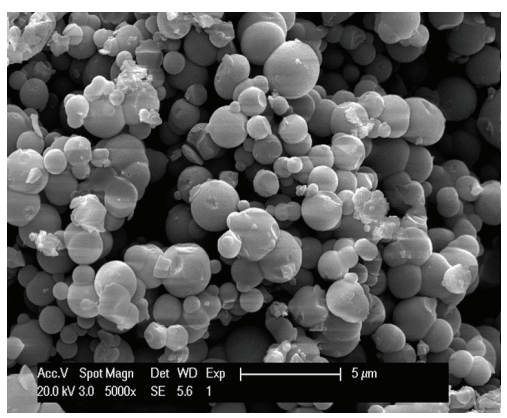

(c)

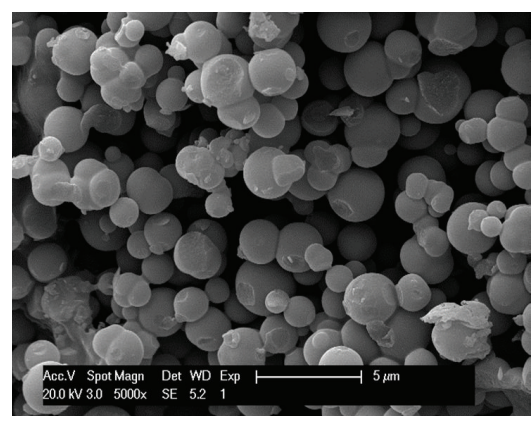

(b)

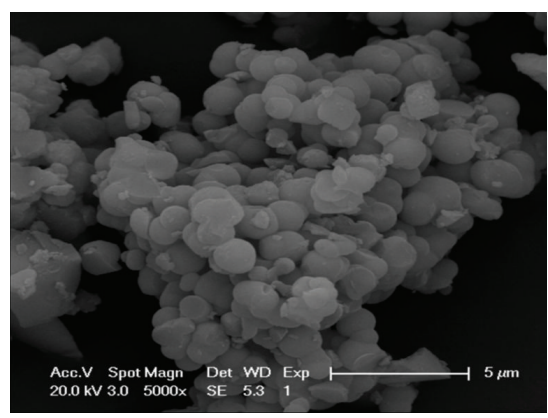

(d)

Figure 2: SEM images of the samples of $\mathrm{C} / \mathrm{TiO}_{2}$ (a), $0.1 \mathrm{wt} \% \mathrm{Pt}-\mathrm{C} / \mathrm{TiO}_{2}$ (b), $0.4 \mathrm{wt} \% \mathrm{Pt}-\mathrm{C} / \mathrm{TiO}_{2}$ (c), and $0.6 \mathrm{wt} \% \mathrm{Pt}-\mathrm{C} / \mathrm{TiO}{ }_{2}$ (d), respectively.

sample with Pt fraction up to $1.2 \mathrm{wt} \%$. TEM image of the sample is shown in Figure 3(d). Interestingly, many spherical shaped particles with diameter of 2 to $5 \mathrm{~nm}$ can be easily found; the lattice fringes of $0.23 \mathrm{~nm}$ match the crystallographic planes of Pt (111) [31]. This result further revealed the presence of $\mathrm{Pt}$ nanoparticles in the resulted samples.

3.3. Formation Mechanism of $\mathrm{TiO}_{2}$ Spheres. Scheme 1 shows possible formation mechanism of $\mathrm{TiO}_{2}$ microspheres. Selfgenerated water from ethanol combustion promoted the hydrolysis of TBOT molecules to form $\mathrm{TiO}_{2}$ nanoparticles. Then nucleation and growth of the particles by coagulation and condensation occurred along the axial direction of the flame. After this period, the nanoparticles are surrounded by the solution, where the water content, gradually increasing in the system, leads to the continuous hydrolysis of TBOT. Nucleated clusters of $\mathrm{TiO}_{2}$ particles quickly aggregated to form solid spheres and crystalized to anatase phase at the elevated temperature [40]. Due to the rapid hydrolysis of TBOT and abrupt shrinkage of the droplets, during the firing in air, the final $\mathrm{TiO}_{2}$ powders consist of a large amount of aggregated spheres [41].

When small amount of $\mathrm{H}_{2} \mathrm{PtCl}_{6} \cdot 6 \mathrm{H}_{2} \mathrm{O}$ is present in the solution, thermal decomposition of $\mathrm{H}_{2} \mathrm{PtCl}_{6} \cdot 6 \mathrm{H}_{2} \mathrm{O}$ would occur under the pyrolysis condition and $\mathrm{Pt}$ particles are simultaneously formed. Since the fast thermolysis and low fraction of $\mathrm{H}_{2} \mathrm{PtCl}_{6} \cdot 6 \mathrm{H}_{2} \mathrm{O}$, the transformation to $\mathrm{Pt}$ reached so fast that the pyrolysis rate can continually exceed the hydrolysis and condensation rate of TBOT. Consequently, it is assumed that $\mathrm{Pt}$ nanoparticles may be embedded in the $\mathrm{C} / \mathrm{TiO}_{2}$ nanocomposite.
3.4. UV-Vis Diffuse Reflectance Spectra. Figure 4 displays the $\mathrm{UV}$-vis diffuse reflectance spectra of the as-prepared samples. A strong absorption in the visible light region is observed for the $\mathrm{Pt}-\mathrm{C} / \mathrm{TiO}_{2}$ photocatalysts. The results also indicate that $\mathrm{PtCl}_{6}{ }^{2-}$ complexes transformed to Pt completely since there is no absorption band from $\mathrm{PtCl}_{6}{ }^{2-}$ complexes, which would exhibit a ligand-to-metal charge transfer band with a maximum at $262 \mathrm{~nm}$ and two bands at around 360 and $480 \mathrm{~nm}$ corresponding to d-d transitions [42, 43]. Furthermore, the absorption edges increased linearly with the increase of $\mathrm{Pt}$ concentration (see Table 1). The value of optical band gap energy of $3.15 \mathrm{eV}$ was calculated for pure $\mathrm{TiO}_{2}$ according to the equation of $E_{g}(\mathrm{eV})=1240 / \lambda_{g}$ [44], which is the same as theoretical value of the anatase phase. Narrowed band gap energies were obtained for the as-synthesized Pt$\mathrm{C} / \mathrm{TiO}_{2}$ composites, and the data are presented in Table 1 . The stronger absorption intensity and longer absorption edge can be attributed to the following factors: (i) carbon in samples can act as sensitizer, which will expand light absorption range into visible region [45]; (ii) $\mathrm{Pt}-\mathrm{C} / \mathrm{TiO}_{2}$ photocatalysts probably exhibit surface plasmon resonance (SPR) due to the presence of Pt particles [46], which will extend the absorption edge to visible light. The SPR peak for the Pt nanoparticles is typically below $450 \mathrm{~nm}$ with broad peak shape; thus usually it can hardly be observed $[47,48]$.

3.5. XPS Analysis. To investigate the chemical state of elements in the sample, XPS analysis is conducted and the results are presented in Figure 5. Figure 5(a) is the XPS spectra of a survey spectrum for a typical sample. Elements of Ti, O, C, and $\mathrm{Pt}$ can be detected in this spectrum. In the Ti 2 p spectrum 


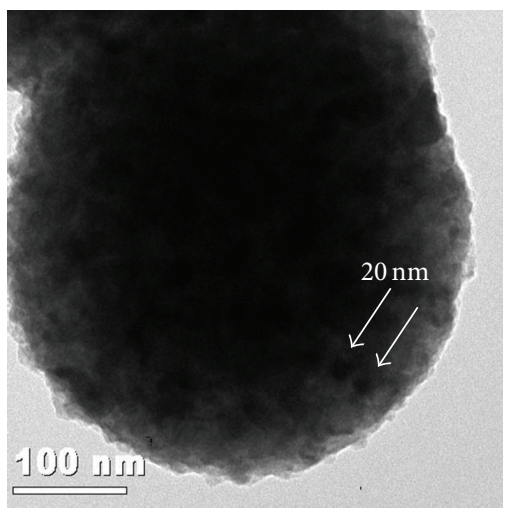

(a)

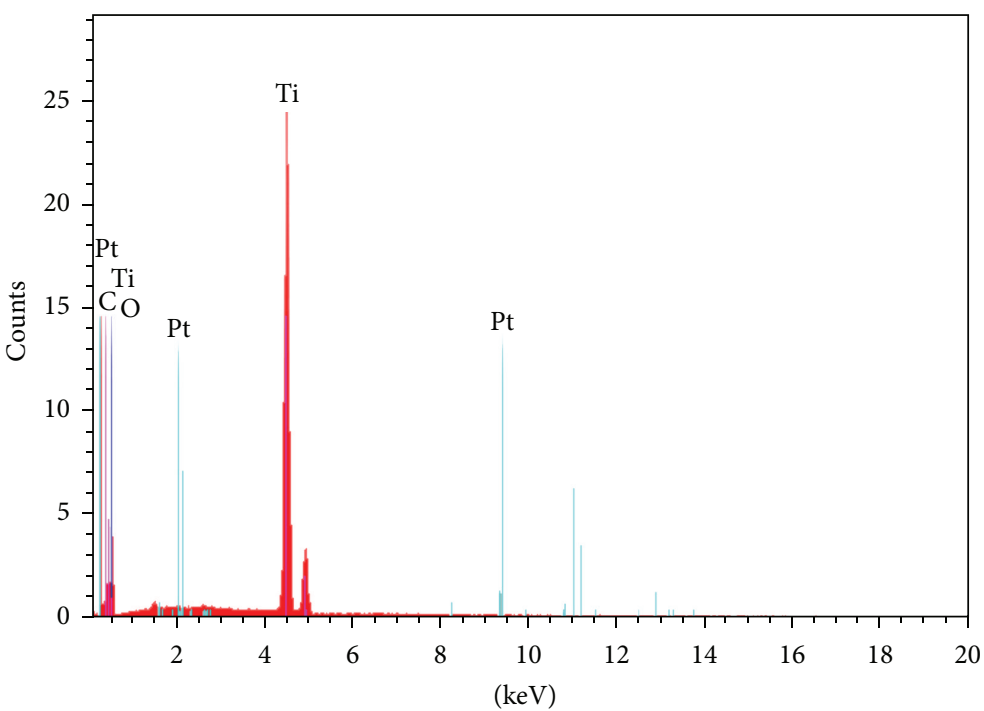

(c)

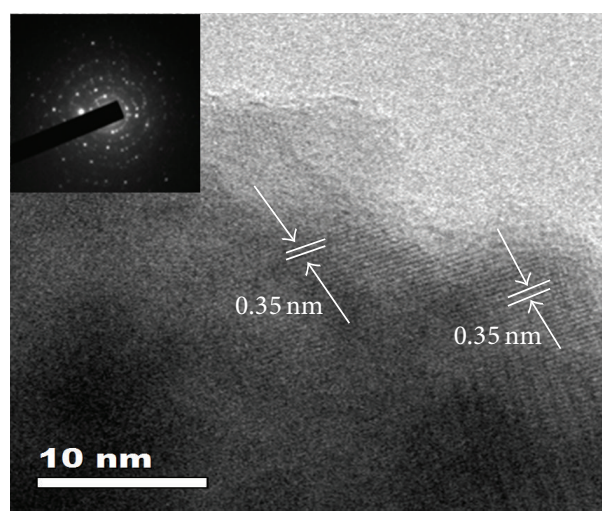

(b)

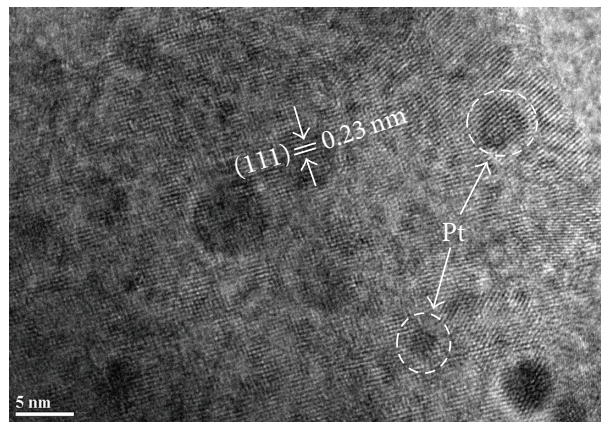

(d)

Figure 3: (a) Representative TEM and HRTEM images of the material: (a) TEM image of 0.4 wt $\%$ Pt-C/TiO ${ }_{2}$; (b) HRTEM image of 0.4 wt\% $\mathrm{Pt}-\mathrm{C} / \mathrm{TiO}_{2}$; inset is the SAED pattern; (c) EDX spectrum of the composite; (d) HRTEM image of $1.2 \mathrm{wt} \% \mathrm{Pt}-\mathrm{C} / \mathrm{TiO}{ }_{2}$.

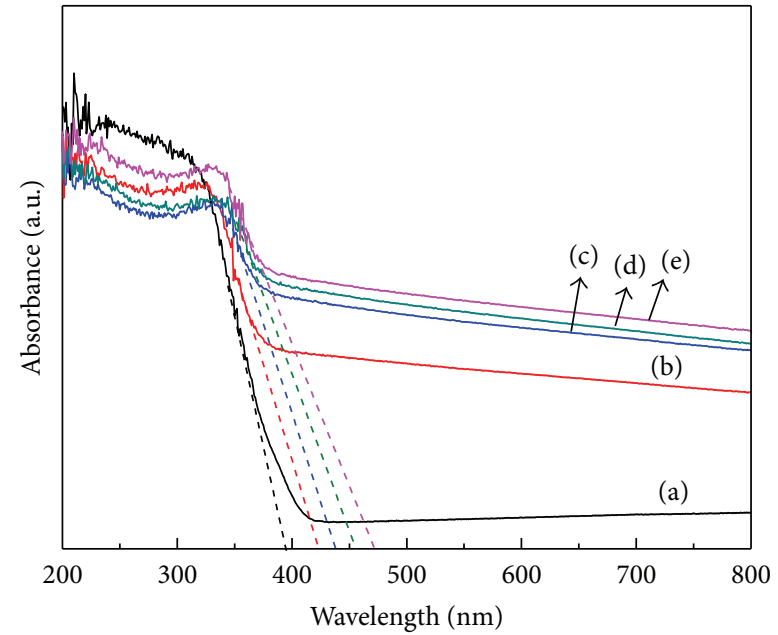

Figure 4: UV-vis diffuse reflectance spectra of $\mathrm{P} 25$ (a), $\mathrm{C} / \mathrm{TiO}_{2}(\mathrm{~b})$, and $\mathrm{Pt}-\mathrm{C} / \mathrm{TiO}_{2}$ composites (c)-(e). The content of $\mathrm{Pt}$ is $0.1 \mathrm{wt} \%$ (c), $0.4 \mathrm{wt} \%(\mathrm{~d})$, and $0.6 \mathrm{wt} \%(\mathrm{e})$, respectively. of $\mathrm{TiO}_{2}$ (Figure 5(b)), there are two peaks centered at $458.5 \mathrm{eV}$ and $464.2 \mathrm{eV}$, which are characteristic of the $\mathrm{Ti} 2 \mathrm{p} 3 / 2$ and $\mathrm{Ti}$ $2 \mathrm{p} 1 / 2$ for $\mathrm{Ti}(\mathrm{IV})[49,50]$, respectively. Figure 5 (c) shows the XPS spectrum of $\mathrm{C} 1 \mathrm{~s}$ of the sample. The peak at $284.6 \mathrm{eV}$ is ascribed to elemental carbon, arising from the incomplete burning of organic compounds [38]. The other small peak at higher binding energies of $288.5 \mathrm{eV}$ is attributed to $\mathrm{C}-\mathrm{O}$ bonds [51], which originates from the insufficient hydrolysis of TBOT. It is to be noted that the absence of the characteristic binding energy of $281.0 \mathrm{eV}$ for $\mathrm{C}-\mathrm{Ti}$ bonds indicates that the carbon did not exist as a dopant; that is, most of the carbon species in $\mathrm{TiO}_{2}$ are present as elemental state [52]. Figure 5(d) displays XPS spectrum for Pt 4f. Two peaks at around $71.4 \mathrm{eV}$ and $74.7 \mathrm{eV}$ are assigned to $4 \mathrm{f} 7 / 2$ and $4 \mathrm{f} 5 / 2$ of $\mathrm{Pt}$ (0), respectively [53]. This result confirmed the presence of metallic Pt in the nanocomposite, which is in line with the observations from TEM and UV-vis DRS.

3.6. TGA Curve. The thermal behavior of a typical sample is probed by measuring thermal analysis and TGA curve is 


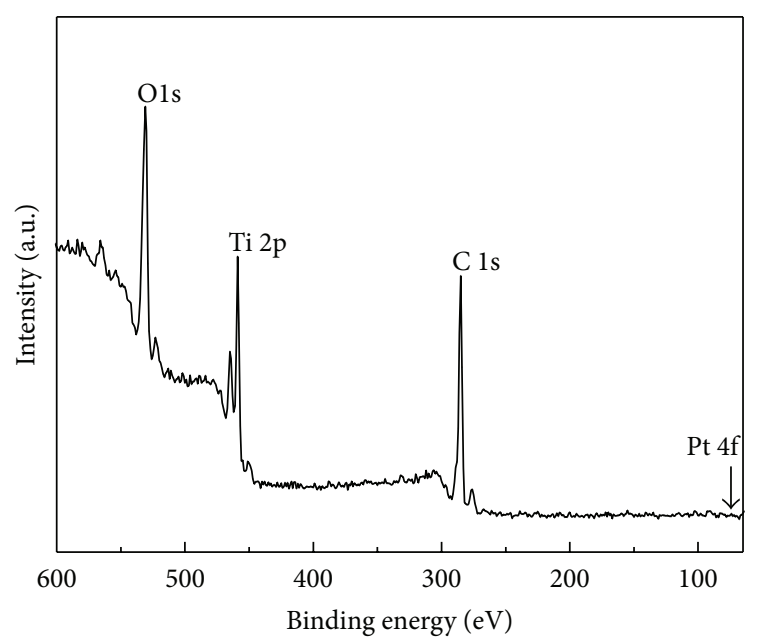

(a)

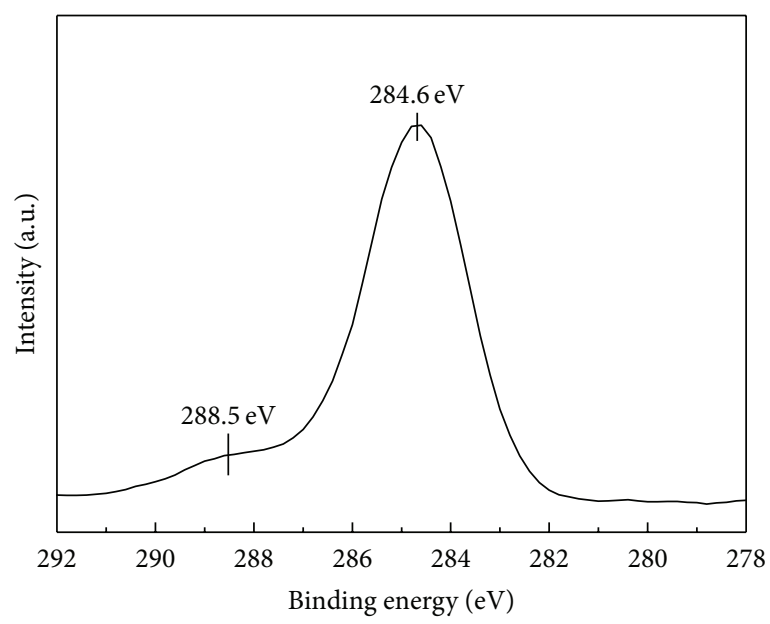

(c)

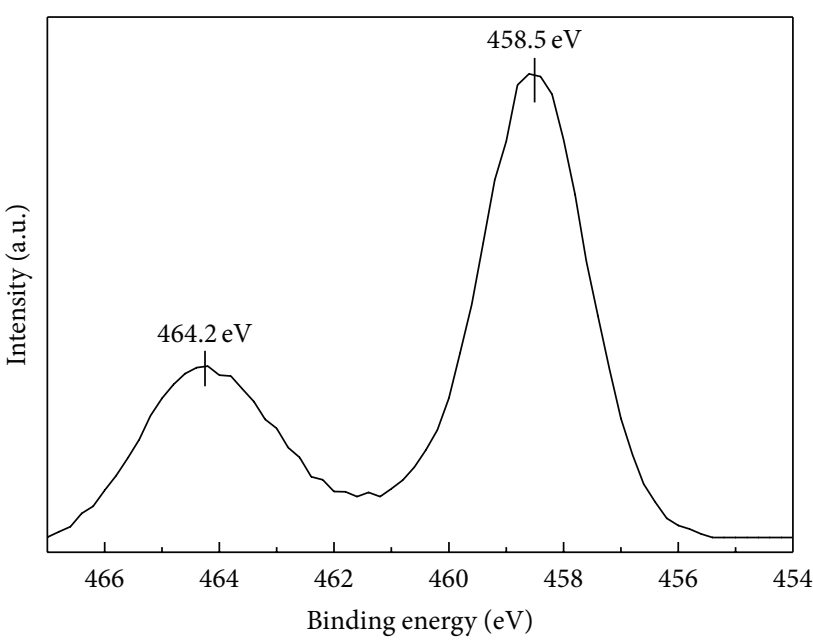

(b)

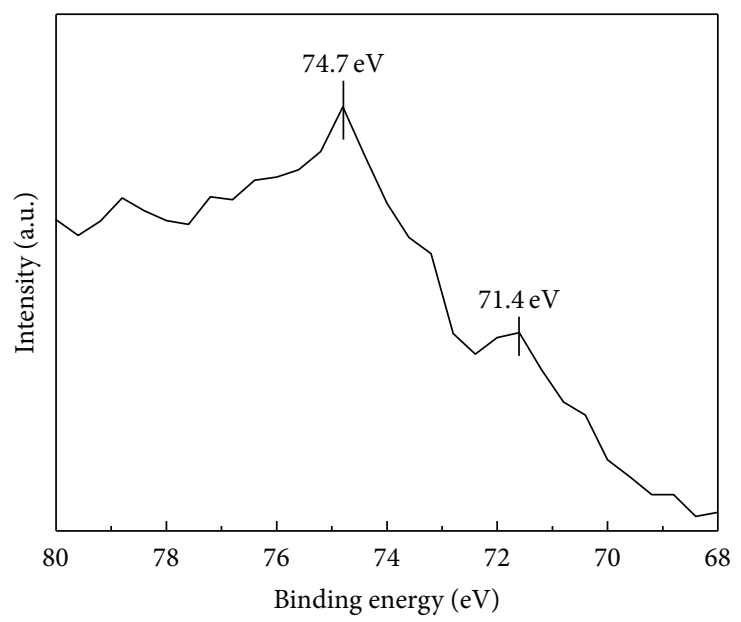

(d)

Figure 5: XPS spectra of $0.4 \mathrm{wt} \% \mathrm{Pt}-\mathrm{C} / \mathrm{TiO}_{2}$ (a), Ti 2p (b), C1s (c), and Pt $4 \mathrm{f}(\mathrm{d})$.

presented in Figure 6. Three main weight losses can be seen at about $100^{\circ} \mathrm{C}, 300^{\circ} \mathrm{C}$, and $600^{\circ} \mathrm{C}$, respectively. The weight loss at $100^{\circ} \mathrm{C}$ originates from water and residual ethanol evaporation. The second step around $300^{\circ} \mathrm{C}$ is ascribed to the decomposition of residual organics on the surface of $\mathrm{TiO}_{2}$. Another peak is attributed to the oxidation of carbon species. The peak relevant to $\mathrm{Pt}$ oxidation has not been found within $800^{\circ} \mathrm{C}$, suggesting the high stability of Pt in the nanocomposite.

3.7. Photocatalytic $\mathrm{H}_{2}$ Production Activity. Photocatalytic activities of the samples were assessed and compared with that of commercial P25 by determining the hydrogen production from aqueous methanol solution. Such a sacrificial agent system is widely used in the studies of photocatalytic $\mathrm{H}_{2}$ production $[34,54,55]$. As depicted in Figure 7 , the hydrogen evolution on P25 is negligible under the applied experimental conditions. It should be reasonable to detect hydrogen evolution from $\mathrm{C} / \mathrm{TiO}_{2}$. Since carbon in $\mathrm{TiO}_{2}$ is likely to carry out a charge transfer process and is responsible for the photosensitization of $\mathrm{TiO}_{2}[45,56]$. The generated hydrogen amount is significantly increased when taking the samples of $\mathrm{Pt}-\mathrm{C} / \mathrm{TiO}_{2}$ as photocatalysts. The improved photocatalytic performance is mainly because the modified $\mathrm{Pt}$ is able to capture electrons and decrease the overpotential of $\mathrm{H}^{+} / \mathrm{H}_{2}$, thus leading to the decrease of the electron-hole pairs recombination [57]. The maximum $\mathrm{H}_{2}$ evolution is achieved for about $5.1 \mu \mathrm{mol}$ on the sample of $0.4 \mathrm{wt} \% \mathrm{Pt}-\mathrm{C} / \mathrm{TiO}_{2}$ after $3 \mathrm{~h}$ irradiation. Significantly, the value is about 22 times that of P25. Nevertheless, the amount of $\mathrm{H}_{2}$ decreased to $4.8 \mu \mathrm{mol}$ when Pt concentration gets to $0.6 \mathrm{wt} \%$. This phenomenon agrees with that of previous reports $[55,58]$. The reason probably is that excessive concentration of Pt nanoparticles will lead to abundant Pt-trapped electrons, which enable easier encounters between the diffusing holes and the Pt-trapped electrons. Consequently, Pt becomes more of electron-hole recombination centers instead of electron-hole separation enhancers [59].

It should be recognized that the activity for $\mathrm{H}_{2}$ evolution is relatively low and more work is necessary to further increase the $\mathrm{H}_{2}$ production. While in this work, the amount of $\mathrm{Pt}$ is relatively smaller to obtain the optimum photocatalytic 


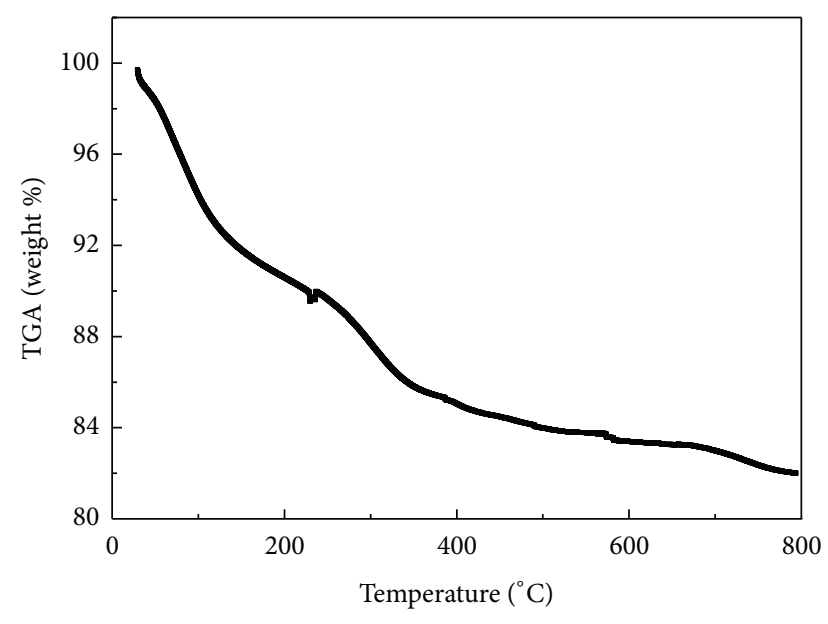

Figure 6: TGA curve of $0.4 \mathrm{wt} \% \mathrm{Pt}-\mathrm{C} / \mathrm{TiO}_{2}$ powders.

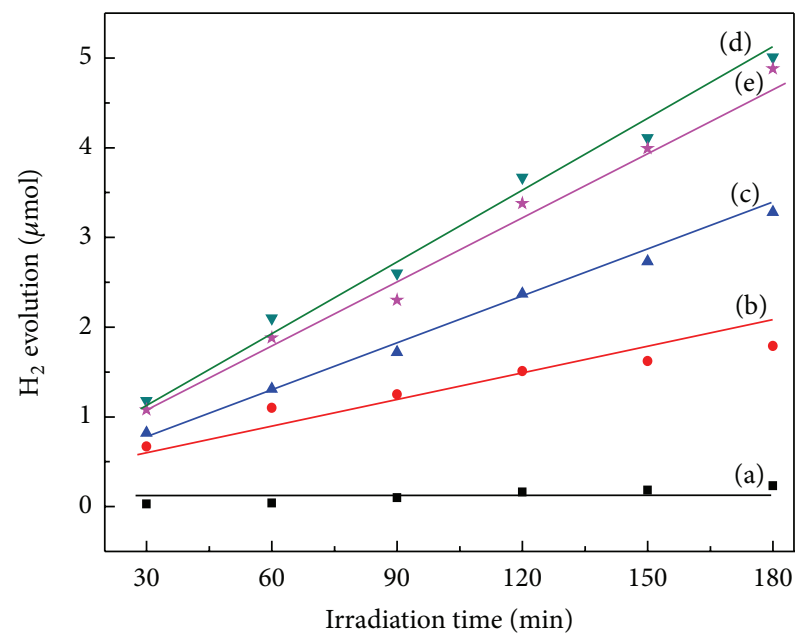

FIGURE 7: Time course of hydrogen evolution under UV-vis light irradiation. (a) $\mathrm{P} 25$, (b) $\mathrm{C} / \mathrm{TiO}_{2}$, (c) $0.1 \mathrm{wt} \% \mathrm{Pt}-\mathrm{C} / \mathrm{TiO}_{2}$, (d) $0.4 \mathrm{wt} \%$ $\mathrm{Pt}-\mathrm{C} / \mathrm{TiO}_{2}$, and (e) $0.6 \mathrm{wt} \% \mathrm{Pt}-\mathrm{C} / \mathrm{TiO}_{2}$.

activity compared with that reported in literatures $[34,60]$. The reduced $\mathrm{Pt}$ content on $\mathrm{TiO}_{2}$ will be important both from a commercial and an ecological point of view. The photocatalytic efficiency of hydrogen evolution is expected to further improve through the better design of hydrogen evolution reactor, the modification of nanocomposites, and the optimization of energy levels of photocatalysts. Corresponding experiments are in progress in this laboratory and the results will be reported in due course.

\section{Conclusions}

In summary, we presented a novel and facile flame thermal method for the preparation of $\mathrm{Pt}$ modified $\mathrm{C} / \mathrm{TiO}_{2}$ microspheres in the first time and demonstrated their high photocatalytic performance for $\mathrm{H}_{2}$ evolution. The as-prepared anatase $\mathrm{TiO}_{2}$ powders show enhanced absorption behavior and obvious red shift in photoresponse towards visible light region. Compared to commercial P25, the resulted samples show significantly improved photocatalytic activity. Given the relatively simple, rapid, scalable, highly efficient, and energysaving properties of this method, it is reasonable to conclude that this technique will be transferable to the fabrication of other modified $\mathrm{TiO}_{2}$ microspheres.

\section{Conflict of Interests}

The authors declare that there is no conflict of interests regarding the publication of this paper.

\section{Acknowledgments}

This work was supported by the Natural Science Foundation of China (no. 21273047) and the National Basic Research Program of China (nos. 2012CB934300, 2011CB933300). The authors thank Ms. Ma Xiaoqing for editing the paper. We also appreciate the referee's very valuable comments, which have greatly improved the quality of the paper.

\section{References}

[1] A. Ishikawa, T. Takata, J. N. Kondo, M. Hara, H. Kobayashi, and K. Domen, "Oxysulfide Sm2Ti2S2O5 as a stable photocatalyst for water oxidation and reduction under visible light irradiation $(\lambda \leq 650 \mathrm{~nm})$," Journal of the American Chemical Society, vol. 124, no. 45, pp. 13547-13553, 2002.

[2] J. R. Ran, J. Zhang, J. G. Yu, M. Jaroniecc, and S. Z. Qiao, Chemical Society Reviews, 2014.

[3] J. Li, X. Chen, M. Sun, and X. Cui, "A facile flame assisted approach to fabricate $\mathrm{Ta}_{2} \mathrm{O}_{5}$ microspheres," Materials Letters, vol. 110, pp. 245-248, 2013.

[4] Y. Wang, J. Yu, W. Xiao, and Q. Lia, "Microwave-assisted hydrothermal synthesis of graphene based $\mathrm{Au}-\mathrm{TiO}_{2}$ photocatalysts for efficient visible-light hydrogen production," Journal of Materials Chemistry A, vol. 2, no. 11, pp. 3847-3855, 2014.

[5] S. K. Parayil, H. S. Kibombo, C. Wu et al., "Synthesis-dependent oxidation state of platinum on $\mathrm{TiO}_{2}$ and their influences on the solar simulated photocatalytic hydrogen production from water," Journal of Physical Chemistry C, vol. 117, no. 33, pp. 16850-16862, 2013.

[6] J. R. Ran, J. G. Yu, and M. Jaroniec, "Ni(OH) $)_{2}$ modified CdS nanorods for highly efficient visible-light-driven photocatalytic $\mathrm{H}_{2}$ generation," Green Chemistry, vol. 13, no. 10, pp. 2708-2713, 2011.

[7] X. Shao, W. Lu, R. Zhang, and F. Pan, "Enhanced photocatalytic activity of $\mathrm{TiO}_{2}-\mathrm{C}$ hybrid aerogels for methylene blue degradation," Scientific Reports, vol. 3, pp. 3018-3026, 2013.

[8] L. Gu, J. Wang, H. Cheng, Y. Zhao, L. Liu, and X. Han, "Onestep preparation of graphene-supported anatase $\mathrm{TiO}_{2}$ with exposed 001 facets and mechanism of enhanced photocatalytic properties," ACS Applied Materials \& Interfaces, vol. 5, no. 8, pp. 3085-3093, 2013.

[9] J. Yu and J. Ran, "Facile preparation and enhanced photocatalytic $\mathrm{H}_{2}$-production activity of $\mathrm{Cu}(\mathrm{OH})_{2}$ cluster modified $\mathrm{TiO}_{2}$," Energy and Environmental Science, vol. 4, no. 4, pp. 13641371, 2011.

[10] H. Bai, Z. Liu, and D. D. Sun, "Facile preparation of monodisperse, carbon doped single crystal rutile $\mathrm{TiO}_{2}$ nanorod spheres 
with a large percentage of reactive (110) facet exposure for highly efficient $\mathrm{H}_{2}$ generation," Journal of Materials Chemistry, vol. 22, no. 36, pp. 18801-18807, 2012.

[11] T. Bak, J. Nowotny, M. Rekas, and C. C. Sorrell, "Photoelectrochemical hydrogen generation from water using solar energy. Materials-related aspects," International Journal of Hydrogen Energy, vol. 27, no. 10, pp. 991-1022, 2002.

[12] S. Chuangchote, J. Jitputti, T. Sagawa, and S. Yoshikawa, "Photocatalytic activity for hydrogen evolution of electrospun $\mathrm{TiO}_{2}$ nanofibers," ACS Applied Materials and Interfaces, vol. 1, no. 5, pp. 1140-1143, 2009.

[13] T. Tachikawa, M. Fujitsuka, and T. Majima, "Mechanistic insight into the $\mathrm{TiO}_{2}$ photocatalytic reactions: design of new photocatalysts," The Journal of Physical Chemistry C, vol. 111, no. 14, pp. 5259-5275, 2007.

[14] J. Shi, X. Yan, H. Cui et al., "Low-temperature synthesis of $\mathrm{CdS} / \mathrm{TiO}_{2}$ composite photocatalysts: influence of synthetic procedure on photocatalytic activity under visible light," Journal of Molecular Catalysis A: Chemical, vol. 356, pp. 53-60, 2012.

[15] M. Xu, P. Da, H. Wu, D. Zhao, and G. Zheng, "Controlled Sn-doping in $\mathrm{TiO}_{2}$ nanowire photoanodes with enhanced photoelectrochemical conversion," Nano Letters, vol. 12, no. 3, pp. 1503-1508, 2012.

[16] X. Chen, H. Li, T. Sun, and X. Cui, "One step flame assisted pyrolysis synthesis of $\mathrm{Fe}$ doped carbon incorporated $\mathrm{TiO} 2$ and its photocatalytic activity," Chemical Journal of Chinese Universities, vol. 34, no. 12, pp. 2855-2960, 2013.

[17] M. C. Wu, J. Hiltunen, A. Sápi et al., "Nitrogen-doped anatase nanofibers decorated with noble metal nanoparticles for photocatalytic production of hydrogen," ACS Nano, vol. 5, no. 6, pp. 5025-5030, 2011.

[18] L. Zhu, J. Xie, X. Cui, J. Shen, X. Yang, and Z. Zhang, "Photoelectrochemical and optical properties of N-doped $\mathrm{TiO}_{2}$ thin films prepared by oxidation of sputtered $\mathrm{TiN}_{x}$ films," Vacuum, vol. 84, no. 6, pp. 797-802, 2010.

[19] P. Song, X. Zhang, M. Sun, X. Cui, and Y. Lin, "Graphene oxide modified $\mathrm{TiO}_{2}$ nanotube arrays: enhanced visible light photoelectrochemical properties," Nanoscale, vol. 4, no. 5, pp. 1800-1804, 2012.

[20] Y. Luo, X. Cui, and J. Xie, "Preparation and visible light photoelectrochemical response of $\mathrm{TiO}_{2}-\mathrm{MoO}_{3}$ composite nanotube thin films," Acta Physico-Chimica Sinica, vol. 27, no. 1, pp. 135142, 2011.

[21] H. Wang, T. T. You, W. W. Shi, J. Li, and L. Guo, "Au/TiO $/ 2 \mathrm{Au}$ as a plasmonic coupling photocatalyst," Journal of Physical Chemistry C, vol. 116, no. 10, pp. 6490-6494, 2012.

[22] Q. Wang, X. Yang, D. Liu, and J. Zhao, "Fabrication, characterization and photocatalytic properties of $\mathrm{Ag}$ nanoparticles modified $\mathrm{TiO}_{2} \mathrm{NTs}$," Journal of Alloys and Compounds, vol. 527, pp. 106-111, 2012.

[23] T. Sreethawong, C. Junbua, and S. Chavadej, "Photocatalytic $\mathrm{H}_{2}$ production from water splitting under visible light irradiation using Eosin Y-sensitized mesoporous-assembled $\mathrm{Pt} / \mathrm{TiO}_{2}$ nanocrystal photocatalyst," Journal of Power Sources, vol. 190, no. 2, pp. 513-524, 2009.

[24] Y. Li, C. Xie, S. Peng, G. Lu, and S. Li, "Eosin Y-sensitized nitrogen-doped $\mathrm{TiO}_{2}$ for efficient visible light photocatalytic hydrogen evolution," Journal of Molecular Catalysis A: Chemical, vol. 282, no. 1-2, pp. 117-123, 2008.

[25] C. Chen, M. Long, H. Zeng et al., "Preparation, characterization and visible-light activity of carbon modified $\mathrm{TiO}_{2}$ with two kinds of carbonaceous species," Journal of Molecular Catalysis A: Chemical, vol. 314, no. 1-2, pp. 35-41, 2009.

[26] J. Zhong, F. Chen, and J. Zhang, "Carbon-deposited $\mathrm{TiO}_{2}$ : synthesis, characterization, and visible photocatalytic performance," The Journal of Physical Chemistry C, vol. 114, no. 2, pp. 933-939, 2010.

[27] H. Li, X. Zhang, X. Cui, and Y. Lin, “TiO 2 nanotubes/MWCNTs nanocomposite photocatalysts: synthesis, characterization and photocatalytic hydrogen evolution under UV-vis light illumination," Journal of Nanoscience and Nanotechnology, vol. 12, no. 3, pp. 1806-1811, 2012.

[28] X. Y. Zhang, H. P. Li, X. L. Cui, and Y. Lin, "Graphene/TiO nanocomposites: synthesis, characterization and application in hydrogen evolution from water photocatalytic splitting," Journal of Materials Chemistry, vol. 20, no. 14, pp. 2801-2806, 2010.

[29] C. Lin, J. Chao, C. Liu, J. Chang, and F. Wang, "Effect of calcination temperature on the structure of a $\mathrm{Pt} / \mathrm{TiO}_{2}$ (B) nanofiber and its photocatalytic activity in generating $\mathrm{H}_{2}$," Langmuir, vol. 24, no. 17, pp. 9907-9915, 2008.

[30] S. Kim, S. Hwang, and W. Choi, "Visible light active platinumion-doped $\mathrm{TiO}_{2}$ photocatalyst," Journal of Physical Chemistry $B$, vol. 109, no. 51, pp. 24260-24267, 2005.

[31] J. Yu, L. Qi, and M. Jaroniec, "Hydrogen production by photocatalytic water splitting over $\mathrm{Pt} / \mathrm{TiO}_{2}$ nanosheets with exposed (001) facets," The Journal of Physical Chemistry C, vol. 114, no. 30, pp. 13118-13125, 2010.

[32] S. Shanmugam and A. Gedanken, "Synthesis and electrochemical oxygen reduction of platinum nanoparticles supported on mesoporous $\mathrm{TiO}_{2}$," The Journal of Physical Chemistry C, vol. 113, no. 43, pp. 18707-18712, 2009.

[33] C. Wang, L. Yin, L. Zhang, N. Liu, N. Lun, and Y. Qi, "Platinumnanoparticle-modified $\mathrm{TiO}_{2}$ nanowires with enhanced photocatalytic property," ACS Applied Materials \& Interfaces, vol. 2, no. 11, pp. 3373-3377, 2010.

[34] T. Sreethawong, S. Laehsalee, and S. Chavadej, "Use of Pt/Ndoped mesoporous-assembled nanocrystalline $\mathrm{TiO}_{2}$ for photocatalytic $\mathrm{H}_{2}$ production under visible light irradiation," Catalysis Communications, vol. 10, no. 5, pp. 538-543, 2009.

[35] A. A. Ismail, D. W. Bahnemann, and S. A. Al-Sayari, "Synthesis and photocatalytic properties of nanocrystalline $\mathrm{Au}, \mathrm{Pd}$ and Pt photodeposited onto mesoporous $\mathrm{RuO}_{2}-\mathrm{TiO}_{2}$ nanocomposites," Applied Catalysis A: General, vol. 431-432, no. 26, pp. 6268, 2012.

[36] Y. Wang, M. Jing, M. Zhang, and J. Yang, "Facile synthesis and photocatalytic activity of platinum decorated $\mathrm{TiO}_{2-x} \mathrm{~N}_{x}$ : perspective to oxygen vacancies and chemical state of dopants," Catalysis Communications, vol. 20, pp. 46-50, 2012.

[37] X. Zhang, Y. Sun, X. Cui, and Z. Jiang, "Carbon-incorporated $\mathrm{TiO}_{2}$ microspheres: facile flame assisted hydrolysis of tetrabutyl orthotitanate and photocatalytic hydrogen production," International Journal of Hydrogen Energy, vol. 37, no. 2, pp. 13561365, 2012.

[38] H. Li, X. Ma, and X. Cui, "Facile flame thermal synthesis of $\mathrm{SiO}_{x}-\mathrm{C} / \mathrm{TiO}_{2}$ microspheres with enhanced photocatalytic performance," Materials Research Express, vol. 1, Article ID 025502, 2014.

[39] W. Li, J. Yang, Z. Wu et al., "A versatile kinetics-controlled coating method to construct uniform porous $\mathrm{TiO}_{2}$ shells for multifunctional core-shell structures," Journal of the American Chemical Society, vol. 134, no. 29, pp. 11864-11867, 2012. 
[40] H. Ma and H. Yang, "A comparative study of $\mathrm{TiO}_{2}$ nanoparticles synthesized in premixed and diffusion flames," Journal of Thermal Science, vol. 19, no. 6, pp. 567-575, 2010.

[41] M. Giannouri, Th. Kalampaliki, N. Todorova et al., "One-Step synthesis of $\mathrm{TiO}_{2}$ /perlite composites by flame spray pyrolysis and their photocatalytic behavior," International Journal of Photoenergy, vol. 2013, Article ID 729460, 8 pages, 2013.

[42] D. L. Swihart and W. R. Mason, "Electronic spectra of octahedral platinum(IV) complexes," Inorganic Chemistry, vol. 9, no. 7, pp. 1749-1757, 1970.

[43] H. Einaga and M. Harada, "Photochemical preparation of poly(N-vinyl-2-pyrrolidone)-stabilized platinum colloids and their deposition on titanium dioxide," Langmuir, vol. 21, no. 6, pp. 2578-2584, 2005.

[44] M. A. Ahmed, "Synthesis and structural features of mesoporous $\mathrm{NiO} / \mathrm{TiO}_{2}$ nanocomposites prepared by sol-gel method for photodegradation of methylene blue dye," Journal of Photochemistry and Photobiology A: Chemistry, vol. 238, pp. 63-70, 2012.

[45] C. Lettmann, K. Hildenbrand, H. Kisch, W. Macyk, and W. F. Maier, "Visible light photodegradation of 4-chlorophenol with a coke-containing titanium dioxide photocatalyst," Applied Catalysis B: Environmental, vol. 32, no. 4, pp. 215-227, 2001.

[46] X. Li, Z. Zhuang, W. Li, and H. Pan, "Photocatalytic reduction of $\mathrm{CO}_{2}$ over noble metal-loaded and nitrogen-doped mesoporous $\mathrm{TiO}_{2}$," Applied Catalysis A: General, vol. 429-430, pp. 31-38, 2012.

[47] O. C. Comptons, C. H. Mullet, S. Chiang, and F. E. Osterloh, "A building block approach to photochemical water-splitting catalysts based on layered niobate nanosheets," The Journal of Physical Chemistry C, vol. 112, no. 15, pp. 6202-6208, 2008.

[48] Z. Zheng, B. Huang, X. Qin, X. Zhang, Y. Dai, and M. Whangbo, "Facile in situ synthesis of visible-light plasmonic photocatalysts $\mathrm{M} @ \mathrm{TiO}_{2}(\mathrm{M}=\mathrm{Au}, \mathrm{Pt}, \mathrm{Ag})$ and evaluation of their photocatalytic oxidation of benzene to phenol," Journal of Materials Chemistry, vol. 21, no. 25, pp. 9079-9087, 2011.

[49] R. Wang, N. Sakai, A. Fujishima, T. Watanabe, and K. Hashimoto, "Studies of surface wettability conversion on $\mathrm{TiO}_{2}$ single-crystal surfaces," Journal of Physical Chemistry B, vol. 103, no. 12 , pp. $2188-2194,1999$.

[50] A. O. T. Patrocínio, E. B. Paniago, R. M. Paniago, and N. Y. M. Iha, "XPS characterization of sensitized $\mathrm{n}-\mathrm{TiO}_{2}$ thin films for dye-sensitized solar cell applications," Applied Surface Science, vol. 254, no. 6, pp. 1874-1879, 2008.

[51] W. Ren, Z. Ai, F. Jia, L. Zhang, X. Fan, and Z. Zou, "Low temperature preparation and visible light photocatalytic activity of mesoporous carbon-doped crystalline $\mathrm{TiO}_{2}$," Applied Catalysis B: Environmental, vol. 69, no. 3-4, pp. 138-144, 2007.

[52] J. A. Rengifo-Herrera, K. Pierzchała, A. Sienkiewicz et al., "Synthesis, characterization, and photocatalytic activities of nanoparticulate $\mathrm{N}, \mathrm{S}$-codoped $\mathrm{TiO}_{2}$ having different surface-tovolume ratios," The Journal of Physical Chemistry C, vol. 114, no. 6, pp. 2717-2723, 2010.

[53] L. P. Xiong, S. Hu, J. W. Hou, K. P. Weng, Y. M. Luo, and T. Z. Yang, "Preparation and catalytic activity of Pt based hydrophobic catalysts adulterated with Fe series elements," Journal of Inorganic Materials, vol. 26, no. 1, pp. 91-96, 2011.

[54] H. Xu, X. Chen, S. Ouyang, T. Kako, and J. Ye, "Size-dependent Mie's scattering effect on $\mathrm{TiO}_{2}$ spheres for the superior photoactivity of $\mathrm{H}_{2}$ evolution," The Journal of Physical Chemistry $C$, vol. 116, no. 5, pp. 3833-3839, 2012.

[55] P. Cheng, Z. Yang, H. Wang et al., " $\mathrm{TiO}_{2}$-graphene nanocomposites for photocatalytic hydrogen production from splitting water," International Journal of Hydrogen Energy, vol. 37, no. 3, pp. 2224-2230, 2012.

[56] X. Zhang, Y. Sun, X. Cui, and Z. Jiang, "A green and facile synthesis of $\mathrm{TiO}_{2}$ /graphene nanocomposites and their photocatalytic activity for hydrogen evolution," International Journal of Hydrogen Energy, vol. 37, no. 1, pp. 811-815, 2012.

[57] W. Lin, W. Yang, I. Huang, T. Wu, and Z. Chung, "Hydrogen production from methanol/water photocatalytic decomposition using $\mathrm{Pt} / \mathrm{TiO}_{2-x} \mathrm{~N}_{x}$ catalyst," Energy \& Fuels, vol. 23, no. 4, pp. 2192-2196, 2009.

[58] M. Zhu, Z. Li, B. Xiao et al., "Surfactant assistance in improvement of photocatalytic hydrogen production with the porphyrin noncovalently functionalized graphene nanocomposite," ACS Applied Materials and Interfaces, vol. 5, no. 5, pp. 17321740, 2013.

[59] C. C. Lin, T. Y. Wei, K. T. Lee, and S. Y. Lu, "Titania and Pt/titania aerogels as superior mesoporous structures for photocatalytic water splitting," Journal of Materials Chemistry, vol. 21, no. 34, pp. 12668-12674, 2011.

[60] P. Wei, J. Liu, and Z. Li, "Effect of Pt loading and calcination temperature on the photocatalytic hydrogen production activity of $\mathrm{TiO}_{2}$ microspheres," Ceramics International, vol. 39, no. 5, pp. 5387-5391, 2013. 

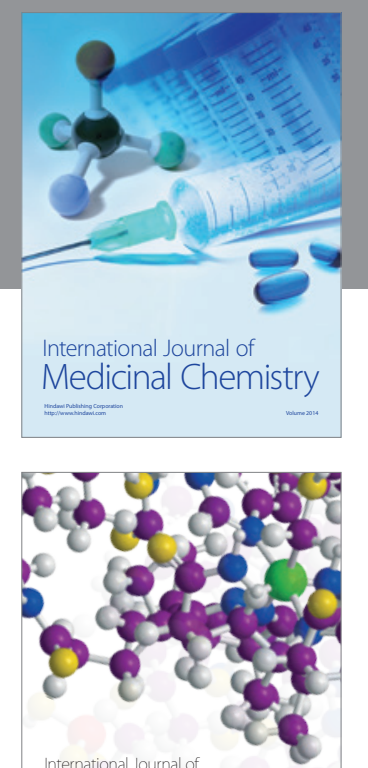

\section{Carbohydrate} Chemistry

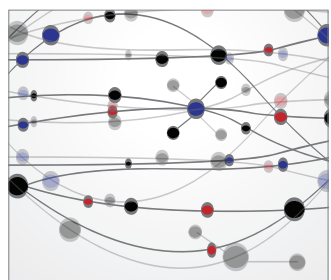

The Scientific World Journal
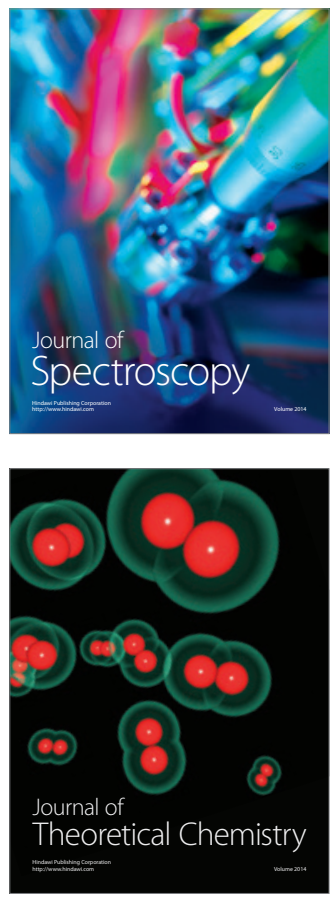
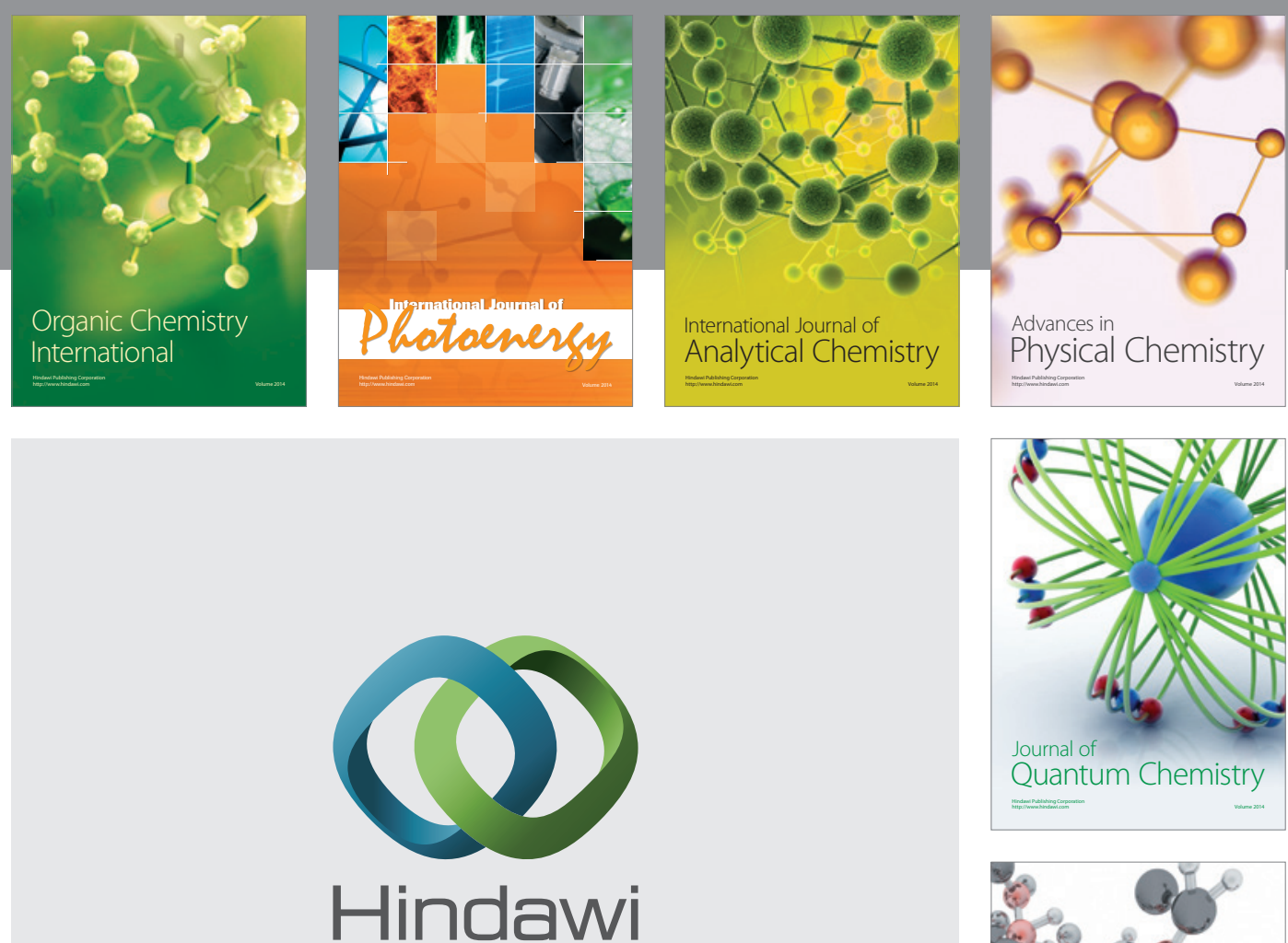

Submit your manuscripts at

http://www.hindawi.com

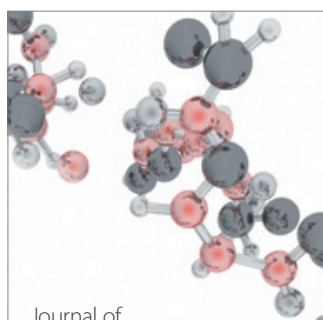

Analytical Methods

in Chemistry

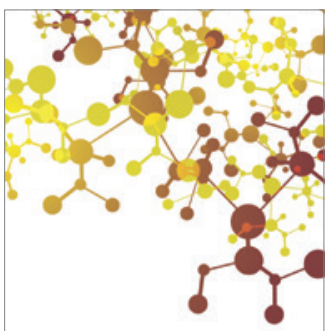

Journal of

Applied Chemistry

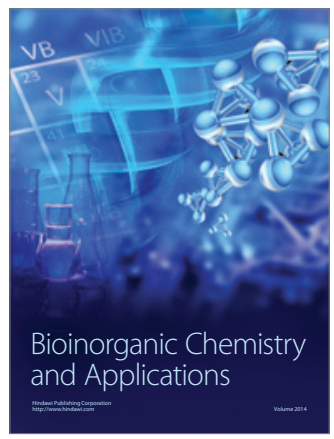

Inorganic Chemistry
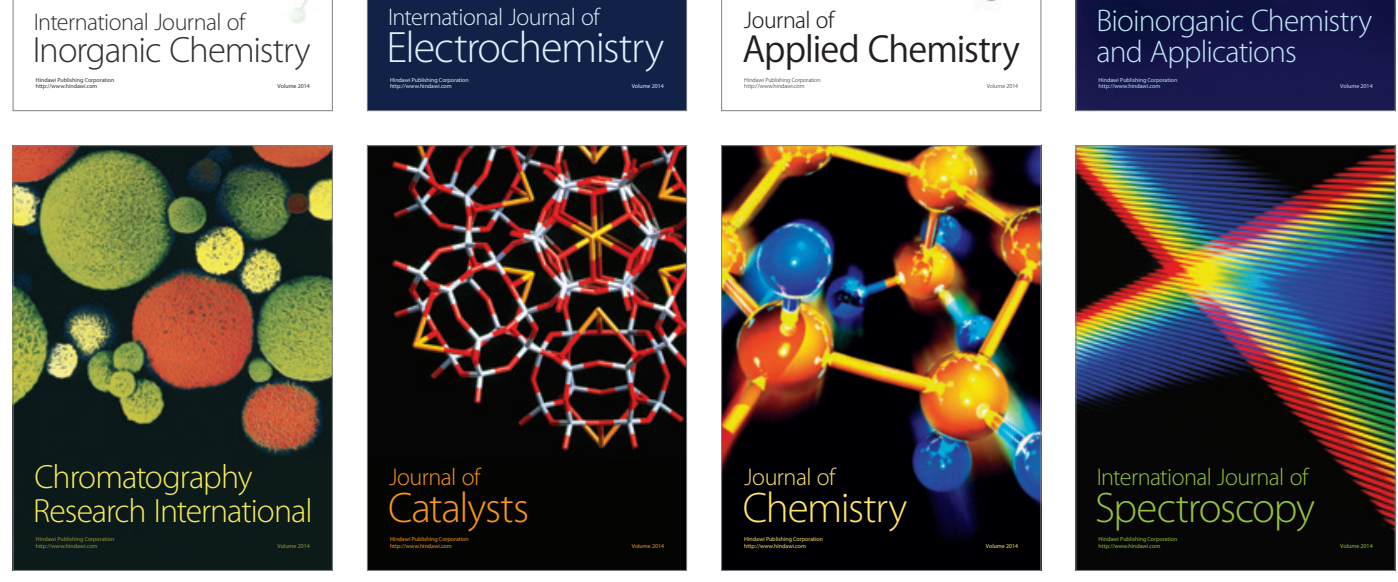